\title{
İnkarsere insizyonel herni kesesi içerisinde perfore apandisit
}

\section{Perforated appendicitis in incarcerated incisional hernia sac}

$\begin{array}{lll}\text { Mehmet Üstün } & \text { Halit Batuhan Demir } & \text { Bengi Balcı Çetindağ } \\ \text { Levent Uğurlu } & \text { Tayfun Kaya } & \text { Cengiz Aydın }\end{array}$

Sağlık Bilimleri Üniversitesi Tepecik Eğitim ve Araştırma Hastanesi, Genel Cerrahi Kliniği, İzmir, Türkiye

Öz

Apendiks vermiform, nadir olarak karın duvarı fıtıkları içerisinde yer alabilmektedir. Akut karın tablosunun ek sık sebebi olan akut apandisit, bu herni keseleri içinde de görülebilmektedir. İnkarsere insizyonel herni kesesi içerisinde perfore apandisit saptanan bir hastaya, apendektomi ve anatomik onarım uyguladık. İnkarsere karın duvarı fıtıkları içerisinde inflame apendiks nadir de olsa görülebilmektedir.

Anahtar Sözcükler: Perfore apandisit, vermiform apendiks, abdominal herni.

\section{Abstract}

Appendix vermiformis is rarely found in the abdominal wall hernias. Acute appendicitis, an additional frequent cause of the acute abdomen, can also occur in these hernia sacs. We performed appendectomy and anatomical repair to a patient who had perforated appendicitis in incarcerated incisional hernia sac. Rarely, inflamed appendix can occur in incarcerated abdominal wall hernias.

Keywords: Perforated appendicitis, vermiform appendix, abdominal hernia.

\section{Giriş}

Apendiks vermiform, nadir de olsa inguinal, obturatuar, umblikal, insizyonel herni gibi karın duvarı fıtıkları içerisinde yer alabilmektedir (1-3). İnguinal herni kesesi içerisinde yer alırsa Amyand herni, femoral herni kesesi içerisinde yer alırsa Garengeot herni şeklinde özel olarak isimlendirilir $(1,4)$. Akut apandisit akut karın tablosunun en sık nedeni olmasının yanında, ender olarak apendiks vermiformun karın duvarı fıtıkları içerisinde yer aldığı durumlarda gelişebilmektedir. Biz, bu olgu sunumunda inkarsere insizyonel herni kesesi içerisinde perfore apandisit saptanan bir olguyu literatürler eşliğinde değerlendirmeyi amaçladık.

Yazışma Adresi: Mehmet Üstün

Sağlık Bilimleri Üniversitesi Tepecik Eğitim ve Araştırma Hastanesi Genel Cerrahi İzmir-Türkiye

Makalenin Geliş Tarihi: 08.08.2017 Kabul Tarihi: 19.09.2017

\section{Olgu Sunumu}

On beş yıl önce nefrolitiyazis tanısı nedeniyle sağ lombotomi insizyon ile sağ nefrektomi uygulanmış 51 yaşındaki erkek hasta, son 2 gündür var olan, sağ lombotomi insizyon hattında lokalize ağrı ve kızarıklık yakınması ile acil servise başvuruyor. Yapılan fizik muayenesinde, sağ lombotomi insizyon skarı bulunan bölgesinde insizyonel hernisi olduğu görüldü.

$\mathrm{Bu}$ bölgede cilt üzerinde kızarıklık, ısı artışı ve palpasyonda yaygın hassasiyet saptandı. Laboratuvar değerlerine bakıldığında lökosit değerinde belirgin artış olduğu görüldü (lökosit: 17.200 hücre/ $\mu \mathrm{L}$ ). Hastanın yapılan yumuşak doku ultrasonografisinde herni kesesi içerisinde barsak ansları ve çevresinde serbest sıvı saptandı. Hasta inkarsere insizyonel herni tanısıyla acil operasyona alındı.

Operasyonda, herni kesesi açıldıktan sonra ilk olarak püy ile karşılaşıldı. Herni kesesi içerisinde çekum ve terminal ileumun yer aldığı, beslenmelerinin kısmi bozuk olduğu ama nekroz gelişmediği gözlendi. Barsak ansları redükte edilince, beslenmesi kısmi olarak bozulmuş olan ansların beslenmesinin normale 
döndüğü görüldü. Redüksiyon sonrası iri, inflame ve mezenterik tarafında yaklaşık $0.5 \mathrm{~cm}$ 'lik perforasyon alanı bulunan apendiks saptandı (Şekil-1). Hastaya apendektomi ve greftsiz anatomik insizyonel herni onarımı uygulandı. Beş gün boyunca intravenöz seftriakson + metronidazol içeren kombine antibiyoterapi uygulandı. Servis izleminde cerrahi alan enfeksiyonu dahil herhangi bir sorun yaşanmadı ve postoperatif 6. günde dreni çekilerek şifa ile taburcu edildi. Operasyon esnasında gönderilen apendektomi materyalinin patoloji sonucu, " $9.5 \times 6 \times 3 \mathrm{~cm}$ boyutlarda, üzerinde yağ doku ve fibrin örtüleri bulunan perfore görünümünde apendiks materyali" şeklinde rapor edildi. Hasta çıkarıldıktan sonra yapılan poliklinik kontrollerinde cerrahi alan enfeksiyonu ya da nüks saptanmadı.

Hastadan tıbbi verilerinin yayınlanabileceğine ilişkin yazılı onam belgesi alındı.

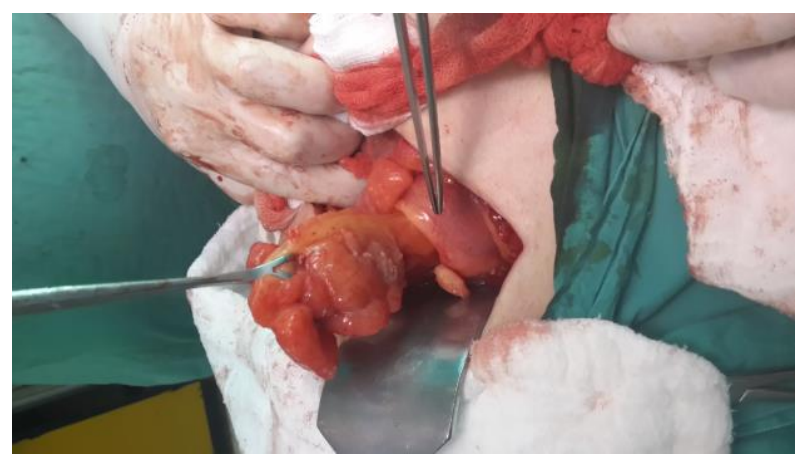

Şekil-1. İnflame ve mezenterik tarafında yaklaşık $0.5 \mathrm{~cm}$ 'lik perforasyon bulunan appendiks.

\section{Tartışma}

İnsizyonel herniler, abdominal cerrahi sonrası görülen en sık komplikasyonlardan biridir ve abdominal cerrahi sonrası görülme oranı \%10-25 arasındadır (5). İnsizyonel herni kesesi içerisinde normal apendiks görülmesi oldukça ender rastlanan bir durumdur. Normal akut apandisit tablosundan farklı olarak herni kesesi içerisindeki apandisitte, etiyolojide ekstralüminal bası sorumludur. Dar fıtık boynu, fıtık kesesi içerisinde oluşan yapışıklıklar, apendiksin kanlanmasını bozarak inflamasyona ve bakteriyel kolonizasyon artışına neden olarak apandisit gelişimine yol açabilir (3).

Apendiksin herni kesesi içerisinde olmasına bağlı olarak klasik akut apandisit semptomlarının görülmemesi, hernial apandisitin operasyon öncesi tanısını koymayı zorlaştırmaktadır (3). Hastanın mevcut klinik tablosu, fizik muayene bulguları ve buna bağlı olarak planlanacak cerrahi sürece göre ileri görüntüleme tetkiki istenebilir. Olgumuzda görüntüleme yöntemi olarak uygulanan yumuşak doku ultrasonografide apandisit lehine bir bulgu saptanmadı. Hasta inkarsere insizyonel herni tanısıyla operasyona alındı.

Insizyonel herni kesesi içerisinde akut apandisit tablosu çok ender görülen bir klinik tablo olduğu için bu durum ile ilgili klinik deneyimler ve yaklaşımlar daha sık görülen Amyand herni tedavi yaklaşımları baz alınarak yapılmaktadır (3). Amyand hernilerde tedavi yaklaşımı apendiksin durumuna göre farklılık göstermektedir. 2007 yılında Lasanoff ve Basson (6) bu ender görülen klinik tablo ile ilgili bir sınıflandırma yapmışlardır. Bu sınıflamaya göre apendiksin normal olduğu durumlarda erken yaş grubu hastalar dışında apendektomi önerilmemektedir. İlerleyen dönemlerde apandisit insidansının yüksek olmasından dolayı erken yaş grubu hastalara apendektomi önerilmektedir. Öte yandan apendiksin normal olduğu durumlarda profilaktik olarak apendektomi uygulanması halen tartışmalıdır (7). Apendiksin inflamasyon durumuna bakılmaksızın her Amyand herni olgusuna apendektomi yapılması gerektiğini savunan çalışmalar mevcuttur $(8,9)$. Profilaktik apendektomiyi savunan görüşe göre operasyon sahasını kontamine etmeden yapılacak dikkatli bir apendektominin morbidite, mortalite, gelecekte oluşabilecek akut apandisit ve buna bağlı anestezi riskini azaltacağı yönündedir (6). Apendiksin inflame ya da perfore olduğu ve apendektomi uygulanan olgularda olası enfeksiyon ve fistül riskinden dolayı prostetik materyal kullanılmaması önerilmektedir (6). Olgumuzda da perfore apandisit tablosu ile karşı karşıya olduğumuz için apendektomiyi takiben anatomik onarım uygulanmıştır. Losanoff ve Basson (6) sınıflaması ile Amyand herni tedavisinde bir standardizasyon başlamasına karşın, halen onaylanması için daha çok prospektif çalışmalara intiyaç vardır (10).

Inkarsere herni kesesi içerisinde nadir de olsa inflame apandisit ile karşılaşılabileceği ve bu yüzden tedavi yaklaşımları hakkında bilgi sahibi olunması gerektiği kanaatindeyiz. 


\section{Kaynaklar}

1. Feitosa Cavalcante J, Melo Teixeira Batista H, Cavalcante Pita Neto I, et al. Amyand's hernia with appendicitis: A case report and integrative review. Case Rep Surg 2015;2015:941039.

2. Alvite Canosa M, Alonso Fernández L, López García S, et al. Acute appendicitis in an incarcerated umbilical hernia. Rev Esp Enferm Dig 2008;100(6):378-9.

3. Sugrue C, Hogan A, Robertson I, Mahmood A, Khan WH, Barry K. Incisional hernia appendicitis: A report of two unique cases and literature review. Int J Surg Case Rep 2013;4(3):256-8.

4. Akopian G, Alexander M. De Garengeot hernia: Appendicitis within a femoral hernia. Am Surg 2005;(6):71:526-7.

5. Muller-Riemenschneider F, Roll S, Friedrich M, et al. Medical effectiveness and safety of conventional compared to laparoscopic incisional hernia repair: A systematic review. Surg Endosc 2007;21(12):2127-36.

6. Losanoff JE, Basson MD. Amyand hernia: A classification to improve management. Hernia 2008;12(3):325-6.

7. Benavides de la Rosa DF, López de Cenarruzabeitia Í, Moreno Racionero F, Merino Peñacoba LM, Beltrán de Heredia J. Case report: Amyand's hernia, diagnosis to consider in a routine procedure. Rev Esp Enferm Dig 2015;107(11):708-9

8. Hutchinson R. Amyand's hernia. J R Soc Med 1993;86(2):104-5.

9. Ofili OP. Simultaneous appendectomy and inguinal herniorrhaphy could be beneficial. Ethiop Med J. 1991;29 (1):37-8.

10. Morales-Cárdenas A, Ploneda-Valencia CF, Sainz-Escárrega VH, et al. Amyand hernia: Case report and review of the literature. Ann Med Surg 2015;4(2):113-5. 